\title{
Physiological Responses During Field Walking Tests in Adults with Bronchiectasis
}

\author{
Simone Dal Corso, Jacqueline C Boldorini, Anderson A de Camargo, Anderson José, \\ Samia Z Rached, Rodrigo A Athanazio, Rafael Stelmach, and Anne E Holland
}

\begin{abstract}
BACKGROUND: Field walking tests are commonly used in patients with chronic pulmonary diseases for assessment of functional capacity. However, the physiological demands and magnitude of desaturation on 6-min walk test (6MWT), incremental shuttle walk test (ISWT), and endurance shuttle walk test (ESWT) have not been investigated in patients with bronchiectasis. The objective of this study was to compare the physiological responses and the magnitude of desaturation of subjects with bronchiectasis when performing the 6MWT, ISWT, and ESWT. METHODS: Thirty-two subjects underwent the 6MWT, ISWT, and ESWT on 3 different days. Pulmonary gas exchange, heart rate, and $\mathrm{S}_{\mathrm{pO}_{2}}$ were measured in all tests. RESULTS: There were no differences in the peak rate of oxygen uptake, ventilation, dyspnea, and leg fatigue between the tests. Equivalent cardiac demand (ie, heart rate at peak) was observed with the 6MWT $(137 \pm 21$ beats/min) and the ESWT $(142 \pm 21$ beats/min), but this was lower in the ISWT $(135 \pm 19$ beats/min) compared to ESWT $(P<.05)$. Most subjects achieved a vigorous exercise intensity (heart rate of $70-90 \%$ of predicted) in all tests. There was no difference in desaturation among the tests (6MWT: $-6.8 \pm 6.6 \%$, ISWT: $-6.1 \pm 6.0 \%$, and ESWT: $-7.0 \pm 5.4 \%)$. CONCLUSIONS: The 6MWT, ISWT, and ESWT induced similar physiological responses at the peak of exercise, eliciting a vigorous exercise intensity. The magnitude of desaturation was similar across tests. This means these tests can be used interchangeably for evaluation of exercise-induced desaturation. Key words: bronchiectasis; exercise test; walk test; oxygen consumption; rehabilitation; oxygen saturation. [Respir Care 2020;65(5):618-624. (C) 2020 Daedalus Enterprises]
\end{abstract}

\section{Introduction}

Bronchiectasis is a chronic disease characterized by irreversible thickening and bronchial dilatation, impaired mucociliary clearance, and repeated bronchial infections that lead to progressive lung damage. ${ }^{1}$ Beyond the severe

Drs Dal Corso, de Camargo, and José, as well as Ms Boldorini, are affiliated with the Postgraduate Program in Rehabilitation Sciences, Universidade Nove de Julho, São Paulo, Brazil. Drs Rached, Athanazio, and Stelmach are affiliated with the Pulmonary Division, Heart Institute, Hospital das Clinicas da Faculdade de Medicina da Universidade de São Paulo, São Paulo, Brazil. Dr Holland is affiliated with the Department of Physiotherapy, Alfred Health, Melbourne, Australia. Dr Holland is affiliated with the Discipline of Physiotherapy, La Trobe University, Melbourne, Australia. Dr Holland is affiliated with the Institute for Breathing and Sleep, Melbourne, Australia.

Dr Dal Corso was supported by Conselho Nacional de Desenvolvimento Científico e Tecnológico (306531/2018-6). Ms Boldorini was supported structural pulmonary abnormalities, exercise intolerance is present in patients with bronchiectasis. ${ }^{2}$ Although the cardiopulmonary exercise test (CPET) conducted in a laboratory has often been considered the accepted standard test of exercise capacity, it is not always available in the settings in which patients receive care, due to the need for expensive equipment and medical staffing. Field walking tests are a simpler solution that have been widely used to

\footnotetext{
by the São Paulo Research Foundation (2013/01863-2). Dr José was supported by Coordenação de Aperfeiçoamento de Pessoal de Nível Superior (1574873). The other authors have disclosed no conflicts of interest.

Correspondence: Simone Dal Corso PT PhD, Postgraduate Program in Rehabilitation Sciences, Universidade Nove de Julho, Rua Vergueiro, 235/249 Liberdade, São Paulo, Brazil 01504-001. E-mail: si.dal.corso@ gmail.com.
}

DOI: 10.4187/respcare.07171 
classify disease severity, estimate prognosis, and assess response to pharmacologic and nonpharmacologic interventions for several chronic pulmonary diseases. ${ }^{3}$ These field walking tests include the incremental shuttle walk test (ISWT), which uses progressive increments in walking speed up to the limit of tolerance; the endurance shuttle walk test (ESWT), which is a constant work load test where the pace of walking does not change; and the 6min walk test (6MWT), which is a self-paced walking test.

Previous research has indicated that, for subjects with pulmonary arterial hypertension, COPD, or interstitial lung disease, the peak oxygen uptake $\left(\dot{\mathrm{V}}_{\mathrm{O}_{2}}\right)$ is comparable between the CPET, ISWT, ESWT, and 6MWT. ${ }^{4-13}$ However, this may be related to disease severity, given that most studies have included only subjects with moderate to severe disease, and one study showed that physiological demands of field walking tests were higher in subjects with greater impairment of lung function. ${ }^{13}$ Desaturation is generally greater during field walking tests compared to the CPET, probably due to the higher amount of exercising muscle mass during walking, pulmonary gas exchange inefficiency, and increased ventilatory demand. ${ }^{6}$ The physiological demands and magnitude of desaturation on field walking tests have not been investigated in people with bronchiectasis, many of whom have better preserved exercise capacity than those with other chronic lung conditions. ${ }^{14}$

On the basis of earlier studies with chronic respiratory diseases, ${ }^{4,11}$ we hypothesized that the pattern of physiological responses would be different on the ISWT compared to the ESWT and the 6MWT, but comparable between the 6MWT and the ESWT. We also anticipated that physiologic responses would be greater at the peak of the ISWT in comparison with the 6MWT and the ESWT. Because walking is the exercise mode shared by these tests, we expected exercise-induced desaturation to be equivalent across these field walking tests. The objective of this study was to compare metabolic and cardiopulmonary responses, as well as the magnitude of desaturation, between the 6MWT, the ISWT, and the ESWT in subjects with bronchiectasis.

\section{Methods}

This is a secondary data analysis of a randomized, double blind, placebo-controlled cross-over study of the effects of bronchodilator therapy on the 6MWT and ESWT performance in subjects with bronchiectasis approved by the Ethics Committee of Universidade Nove de Julho (313778) and Universidade de São Paulo (451538).

Subjects were recruited from the obstructive disease outpatient clinic at the Hospital das Clínicas da Universidade de São Paulo, and the assessments were performed in

\section{QUICK LOOK}

\section{Current knowledge}

Impaired exercise capacity is a problem shared by patients with different chronic lung diseases. The 6min walk test, the incremental shuttle walk test, and the endurance shuttle walk test have been used widely to evaluate functional capacity in this population. Despite the differences in the protocols, these field walking tests converge with similar responses at the peak of exercise.

\section{What this paper contributes to our knowledge}

In subjects with bronchiectasis, field walking tests elicited a vigorous-intensity exercise leading to similar oxygen uptake and ventilation at the peak of exercise. Exercise-induced desaturation was equivalent across tests. Based on our results, field walking tests can be used interchangeably for the evaluation of exerciseinduced desaturation.

the pulmonary rehabilitation center at the Universidade Nove de Julho. After written and verbal explanations, all participants signed a consent form before starting the assessments.

Subjects with bronchiectasis, $\geq 18$ y old who were clinically stable (ie, no changes in medication, sputum color, or shortness of breath in the preceding 4 weeks) were included. Bronchiectasis was diagnosed by the medical staff of the obstructive disease out-patient clinic at the Hospital das Clínicas da Universidade de São Paulo based on clinical and tomographic evaluations according to international guidelines. ${ }^{15}$ Patients were excluded if they had a smoking history ( $\geq 10$ pack-years) to avoid possible concomitant COPD; neuromuscular or musculoskeletal disease; heart disease; primary diagnosis of other pulmonary diseases; or using long-term oxygen therapy at rest, which would invalidate the $\dot{\mathrm{V}}_{\mathrm{O}_{2}}$ measurement.

On the first day, subjects performed spirometry, ${ }^{16-17}$ answered the modified Medical Research Council dyspnea scale, ${ }^{18}$ and performed the ISWT (30 min after the spirometry). This test was performed first due to the requirement to use the ISWT results to set the constant walking speed for the ESWT. After at least $48 \mathrm{~h}$, they were randomized to either 6MWT or ESWT. On a third day, subjects underwent the remaining test (6MWT or ESWT). The 6MWT and ESWT were performed after 15min of bronchodilator therapy (Albuterol, $100 \mu \mathrm{g}$, four inhalations). 


\section{Assessments}

The ISWT was performed according to the original description. ${ }^{19}$ Two cones were placed $0.5 \mathrm{~m}$ from each edge to mark a distance of $10 \mathrm{~m}$. Subjects followed a predetermined speed imposed by an audible prerecorded signal. The test finished when the subject was $>0.5 \mathrm{~m}$ from the cone when the audio signal sounded for 2 consecutive attempts. Two tests were performed on the same day (at least 30 min apart, when the physiological parameters were similar to the first test). ${ }^{3}$

The ESWT was performed as previously described. ${ }^{20}$ The speed for ESWT was set at $85 \%$ of the peak $\dot{\mathrm{V}}_{\mathrm{O}_{2}}$ estimated from the following equation: peak $\dot{\mathrm{V}}_{\mathrm{O}_{2}}=4.19+$ $0.025 \times$ ISWT distance. $^{20}$

The 6MWT was performed according to the international recommendations in a hallway $30 \mathrm{~m}$ long. ${ }^{3}$ Two tests were performed on the same day (at least $30 \mathrm{~min}$ apart, when the physiological parameters were similar to the first test). ${ }^{3}$

\section{Physiologic Measures}

During the 3 field walking tests, a portable metabolic system (VO2000, Medical Graphics, St Paul, Minnesota) was used to measure pulmonary gas exchange. Before every test, the system was calibrated according to the manufacturer's recommendations. Measurements were performed at rest in the sitting position and during each field walking test. Metabolic and ventilatory variables were recorded breath by breath and expressed as $30 \mathrm{~s}$ means. Heart rate (Polar Precision Performance, Polar Electro Oy, Kem-skin, Finland) and oxygen saturation $\left(\mathrm{S}_{\mathrm{pO}_{2}}\right)$ (Model 9500, Nonin, Onyx 9500 Digital Fingertip Pulse Oximeter, Plymouth, Minnesota) were continuously measured during the test. Arterial blood pressure and Borg scale (0-10) score for dyspnea and lower limb fatigue were obtained at rest and at the end of each test. Data from the test with longest distance walked for both the 6MWT and the ISWT were used for analysis. Maximum predicted heart rate was estimated by 220 - age in years. Exercise intensity was classified based on a percentage of maximum heart rate achieved at the peak of field walking tests as follows: light intensity was from 40 to $<55 \%$, moderate intensity was from 55 to $<70 \%$, vigorous intensity was from 70 to $<90 \%$, and high intensity was $\geq 90 \%{ }^{21}$ A decrease in $\mathrm{S}_{\mathrm{pO}_{2}}$ between rest and exercising $\left(\Delta \mathrm{S}_{\mathrm{pO}_{2}}\right)$ of $\geq 4 \%$ was considered desaturation. $^{22}$

\section{Statistical Analysis}

The data analysis was performed using SPSS 20.0 for Windows (SPSS, Chicago, Illinois). The Shapiro-Wilk test was used to verify the normality of data distribution. Parametric data were expressed as mean \pm SD. Nonpara-
Table 1. Subject Characteristics

\begin{tabular}{lcc}
\hline \hline \multicolumn{1}{c}{ Variables } & Mean $\pm \mathrm{SD}$ & Range \\
\hline Age, $\mathrm{y}$ & $44 \pm 17$ & $18-70$ \\
Body mass index, $\mathrm{kg} / \mathrm{m}^{2}$ & $24 \pm 6$ & $14-35$ \\
$\mathrm{mMRC}^{2}$ score & & $0-4$ \\
$\mathrm{FVC}, \mathrm{L}$ & $1(0.25-2.0)$ & $1.1-4.1$ \\
$\mathrm{FVC}, \%$ predicted & $2.4 \pm 0.8$ & $37.5-127.9$ \\
$\mathrm{FEV}_{1}, \mathrm{~L}$ & $73 \pm 22$ & $0.7-3.3$ \\
$\mathrm{FEV}_{1}, \%$ predicted & $1.5 \pm 0.6$ & $22-135$ \\
$\mathrm{FEV}_{1} / \mathrm{FVC}, \%$ & $57 \pm 26$ & $30-85$ \\
& $64 \pm 15$ & \\
$N=32$ subjects. & & \\
$*$ Median (interquartile range). & \\
mMRC $=$ modified Medical Research Council dyspnea scale & \\
\hline
\end{tabular}

metric data were expressed as median (interquartile range). Repeated measures analysis of variance with Tukey's post hoc tests were used to analyze physiological responses during the tests. Categorical data across the walking tests were compared with the Kruskal-Wallis test. Paired ttests were used to compare mean velocity between 6 MWT and ESWT. $P<.05$ was considered statistically significant.

\section{Results}

Fifty-one patients with bronchiectasis were assessed for eligibility; 13 refused to participate in the study, one was excluded due to the coexistence of severe heart disease, 2 had orthopedic problems, and 3 were oxygen-dependent at rest. Characteristics of the 32 subjects (18 female) included in the study are presented in Table 1 . The median time of the diagnostic was $12 \mathrm{y}$ (interquartile range: $8.25-19.3 \mathrm{y}$ ). Subjects had a wide range of disease severity, and most had low levels of dyspnea.

Performance, physiological responses, and perception of effort at the peak of exercise for each test are shown in Table 2. Distance walked and exercise duration differed significantly among tests. However, there was no difference in peak $\dot{\mathrm{V}}_{\mathrm{O}_{2}}, \dot{\mathrm{V}}_{\mathrm{E}}$, and $\mathrm{S}_{\mathrm{pO}_{2}}$ across the tests. Heart rate was higher in both the 6MWT and the ESWT than in the ISWT. No difference was observed in the mean walking velocity between the 6MWT and the ESWT $(0.07$ $\mathrm{m} / \mathrm{s}, 95 \% \mathrm{CI}-0.084$ to 0.22 ). Despite differences in test duration, the number of subjects who finished the test with symptoms of dyspnea equivalent to symptoms of leg fatigue, dyspnea superior to leg fatigue, and leg fatigue superior to dyspnea were similar among the tests (Table 2).

The pattern of $\dot{\mathrm{V}}_{\mathrm{O}_{2}}$, ventilation, heart rate, and $\mathrm{S}_{\mathrm{pO}_{2}}$ responses during the 3 field walking tests is shown in Figure 1. The 6MWT and ESWT presented an immediate increase in $\dot{\mathrm{V}}_{\mathrm{O}_{2}}$, ventilation, and heart rate from the beginning up to the first minutes, and then a steady state until the end of the 
Table 2. Results of Walking Tests

\begin{tabular}{|c|c|c|c|c|}
\hline Variables & $6 \mathrm{MWT}$ & ISWT & ESWT & $P$ \\
\hline Distance, $\mathrm{m}$ & $528.7 \pm 83.4^{*}$ & $444.4 \pm 117.7 \dagger$ & $907.0 \pm 598.8$ & $<.001$ \\
\hline Time, min & $6.0 \pm 0.0$ & $7.0 \pm 1.3$ & $10.2 \pm 6.4$ & $<.001$ \\
\hline Mean velocity, $\mathrm{m} / \mathrm{s}$ & $1.47 \pm 0.23$ & NA & $1.40 \pm 0.35$ & $.26 \ddagger$ \\
\hline$\dot{\mathrm{V}}_{\mathrm{O}_{2}}, \mathrm{~L}$ & $1.19 \pm 0.43$ & $1.23 \pm 0.37$ & $1.25 \pm 0.46$ & .60 \\
\hline$\dot{\mathrm{V}}_{\mathrm{O}_{2}}, \mathrm{~mL} / \mathrm{kg} / \mathrm{min}$ & $2.7 \pm 6.5$ & $21.6 \pm 6.1$ & $21.8 \pm 7.3$ & .39 \\
\hline$\dot{\mathrm{V}}_{\mathrm{O}_{2}}, \%$ predicted & $73.2 \pm 26.2$ & $75.3 \pm 20.2$ & $75.8 \pm 25.4$ & .56 \\
\hline$\dot{\mathrm{V}}_{\mathrm{CO}_{2}}, \mathrm{~L}$ & $1.28 \pm 0.49$ & $1.33 \pm 0.52$ & $1.39 \pm 0.62$ & .23 \\
\hline$\dot{\mathrm{V}}_{\mathrm{E}}, \mathrm{L}$ & $28.1 \pm 9.4$ & $28.5 \pm 8.2$ & $3.5 \pm 11.4$ & .09 \\
\hline$\dot{\mathrm{V}}_{\mathrm{E}} / \mathrm{MVV}$ (range) & $0.49 \pm 0.15(0.18-0.77)$ & $0.50 \pm 0.15(0.23-0.76)$ & $0.53 \pm 0.16(0.18-0.79)$ & .19 \\
\hline $\mathrm{S}_{\mathrm{pO}_{2}}, \%$ & $88 \pm 8$ & $89 \pm 7$ & $88 \pm 6$ & .38 \\
\hline$\Delta \mathrm{S}_{\mathrm{pO}_{2}}$ & $-6.8 \pm 6.6$ & $-6.1 \pm 6.0$ & $-7.0 \pm 5.4$ & .45 \\
\hline$\Delta \mathrm{S}_{\mathrm{pO}_{2}} \geq-4 \%, n$ & 19 & 19 & 23 & .49 \\
\hline Heart rate, beats/min & $137 \pm 21$ & $135 \pm 19 \dagger$ & $142 \pm 21$ & .043 \\
\hline Heart rate, $\%$ maximum predicted & $78 \pm 11$ & $77 \pm 9 \dagger$ & $82 \pm 10$ & .031 \\
\hline Light intensity, $n$ & 1 & 1 & NA & NA \\
\hline Moderate intensity, $n$ & 8 & 4 & 5 & $>.99$ \\
\hline Vigorous intensity, $n$ & 23 & 27 & 19 & $>.99$ \\
\hline High intensity, $n$ & NA & NA & 8 & NA \\
\hline Dyspnea & $4 \pm 2$ & $5 \pm 2$ & $5 \pm 2$ & .31 \\
\hline Leg fatigue & $4 \pm 2$ & $4 \pm 2$ & $4 \pm 2$ & .29 \\
\hline Dyspnea $=$ leg fatigue, $n$ & 12 & 9 & 12 & $>.99$ \\
\hline Dyspnea $>$ leg fatigue, $n$ & 8 & 12 & 9 & $>.99$ \\
\hline Dyspnea $<$ leg fatigue, $n$ & 12 & 11 & 11 & $>.99$ \\
\hline $\begin{array}{l}N=32 \text { subjects. } \\
* 6 \mathrm{MWT} \text { versus ISWT and ESWT. } \\
\dagger \text { ISWT versus ESWT. } \\
\ddagger \text { Paired } t \text { test: } 6 \text { MWT versus ESWT. } \\
6 \mathrm{MWT}=6 \text {-min walk test } \\
\text { ISWT }=\text { incremental shuttle walk test } \\
\text { ESWT = endurance shuttle walk test } \\
\dot{\mathrm{V}}_{\mathrm{O}_{2}}=\text { oxygen uptake } \\
\dot{\mathrm{V}}_{\mathrm{CO}_{2}}=\text { carbon dioxide production } \\
\mathrm{MVV}=\text { minute voluntary ventilation } \\
\dot{\mathrm{V}}_{\mathrm{E}}=\text { ventilation } \\
\mathrm{NA}=\text { not applicable }\end{array}$ & & & & \\
\hline
\end{tabular}

tests. The ISWT exhibited a linear increase in physiological responses according to increments in the walking speed during the test. Peak $\dot{\mathrm{V}}_{\mathrm{O}_{2}}$ did not differ between the ISWT and 6MWT (mean difference: $44 \mathrm{~mL} / \mathrm{m}, 95 \% \mathrm{CI}-110$ to 198 $\mathrm{mL} / \mathrm{m}$ ), between the ISWT and ESWT (mean difference: $-11 \mathrm{~mL} / \mathrm{m}, 95 \% \mathrm{CI}-172$ to -151$)$, and between the 6MWT and ESWT (mean difference: $-55 \mathrm{~mL} / \mathrm{m}, 95 \% \mathrm{CI}$ -165 to $55 \mathrm{~mL} / \mathrm{m})$. Ventilation at the peak of the ISWT was comparable to that achieved in the 6MWT (mean difference: $0.4 \mathrm{~L} / \mathrm{m}, 95 \% \mathrm{CI}-2.3$ to $3.1 \mathrm{~L} / \mathrm{m}$ ) and in the ESWT (mean difference: $-2.1 \mathrm{~L} / \mathrm{m}, 95 \% \mathrm{CI}-5.5$ to $1.4 \mathrm{~L} / \mathrm{m}$ ), and it was equivalent between the 6MWT and the ESWT (mean difference: $-2.5 \mathrm{~L} / \mathrm{m}, 95 \% \mathrm{CI}-5.2$ to $0.3 \mathrm{~L} / \mathrm{m}$ ). Significantly, lower values of cardiac demand were observed in the ISWT but were similar between the 6MWT and the ESWT (Table 2).

Field walking tests imposed vigorous exercise intensity for the majority of subjects (Table 2). High exercise intensity was achieved by 8 subjects on the ESWT only; their baseline characteristics did not differ from the remainder of the sample (age: $45 \pm 18 \mathrm{y}$, FVC: $2.4 \pm 0.9 \mathrm{~L}$ corresponding to $73 \pm 26 \%$ of predicted, $\mathrm{FEV}_{1}: 1.6 \pm 0.8 \mathrm{~L}$ corresponding to $60 \pm 32 \%$ of predicted). For these subjects, on average, ESWT lasted $13.0 \pm 4.4$ min (range: 7.3 to $20 \mathrm{~min}$ ), and 6 subjects presented with desaturation $\left(\mathrm{S}_{\mathrm{pO}_{2}}\right.$ at the peak: $\left.89.0 \pm 5.9 \%\right)$.

\section{Discussion}

This is the first study to compare physiological responses and perception of effort during field walking tests in subjects with bronchiectasis. As expected, the 6MWT and the ESWT presented physiological responses corresponding to a constant work rate test, whereas the ISWT exhibited incremental physiological demand. Despite inherent differences related to how each field walking test is performed, metabolic $\left(\dot{\mathrm{V}}_{\mathrm{O}_{2}}\right.$ and $\left.\dot{\mathrm{V}}_{\mathrm{CO}_{2}}\right)$, and ventilatory $\left(\dot{\mathrm{V}}_{\mathrm{E}}\right.$ and $\dot{\mathrm{V}}_{\mathrm{E}} / \mathrm{MVV}$ [ie, minute voluntary ventilation]) demands, as well as $\mathrm{S}_{\mathrm{pO}_{2}}$ 

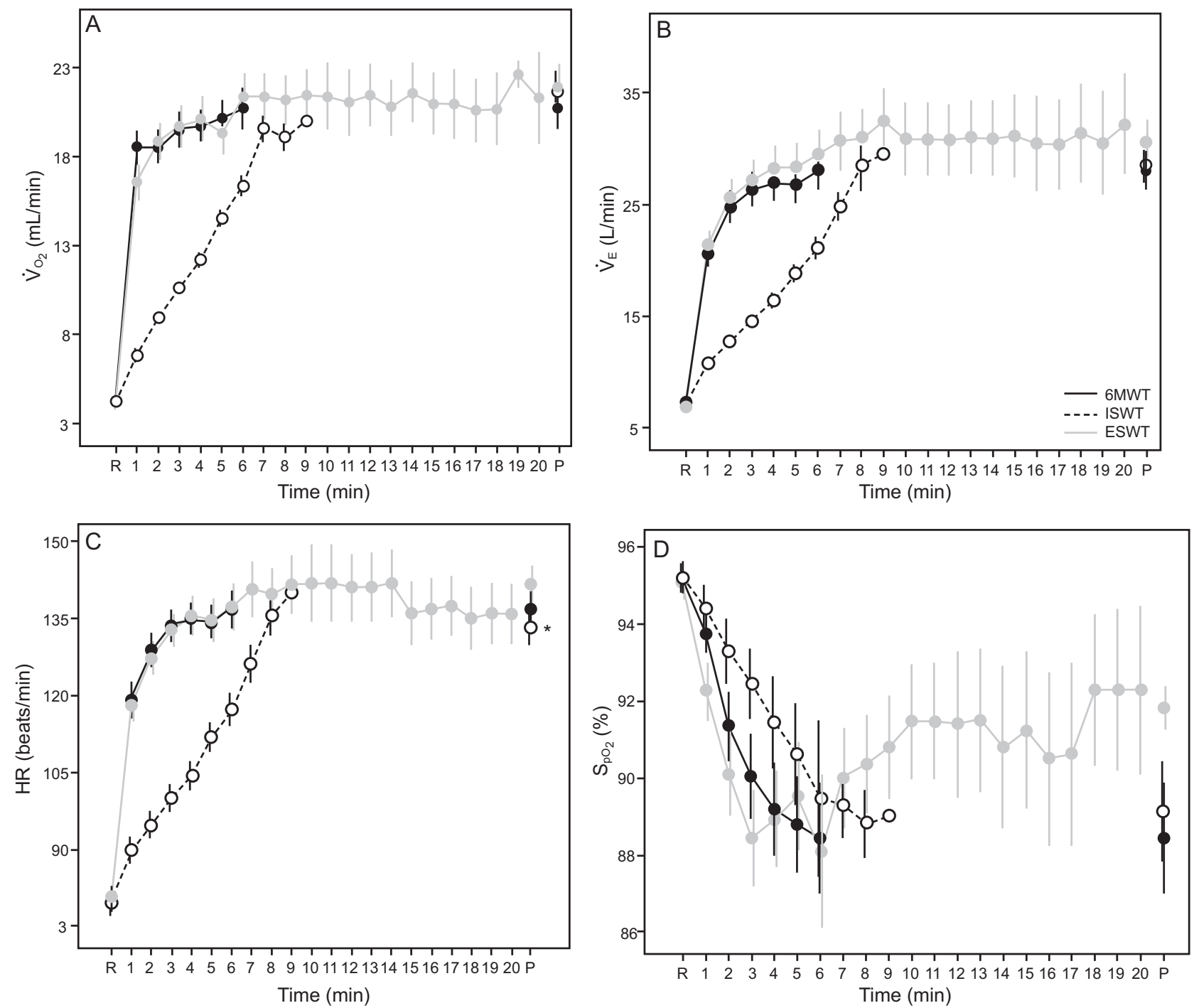

Fig. 1. Physiological responses across the field walking tests: $(A)$ oxygen uptake, $\dot{\mathrm{V}}_{2}$; (B) ventilation, $\dot{\mathrm{V}}_{\mathrm{E}}$; (C) heart rate; (D) oxygen saturation measured via pulse oximetry, $\mathrm{S}_{\mathrm{pO}_{2}} . \mathrm{R}=$ rest; $\mathrm{P}=$ peak. Data are presented as mean \pm standard error. ${ }^{*} P<.05$ ISWT vs. ESWT.

at the peak of exercise, were similar across tests. Equivalent cardiac demand (heart rate at peak) was observed between the 6MWT and the ESWT but was lower in the ISWT.

We had anticipated that $\dot{\mathrm{V}}_{\mathrm{O}_{2}}$ and heart rate would be higher at the end of the ISWT because of its incremental nature. However, $\dot{\mathrm{V}}_{\mathrm{O}_{2}}$ was comparable across tests, whereas heart rate on the ISWT was not different from that achieved in the 6MWT but was lower than that obtained at the end of the ESWT. In some previous reports in subjects with chronic lung diseases, the ISWT, 6MWT, and ESWT elicited compatible values of peak $\dot{\mathrm{V}}_{\mathrm{O}_{2}}, \dot{\mathrm{V}}_{\mathrm{E}}$, and heart rate. ${ }^{4,10,11}$ In previous studies with comparable peak $\dot{\mathrm{V}}_{\mathrm{O}_{2}}, \dot{\mathrm{V}}_{\mathrm{E}}$, and heart rate between ISWT and 6MWT, ${ }^{10,11}$ subjects met, on average, the criteria of ventilatory limitation $\left(\dot{\mathrm{V}}_{\mathrm{E}} / \mathrm{MVV}>80 \%\right)$ during these walking tests, which possibly prevented them from reaching substantial cardiac overload. The ventilatory limitation was not a finding for subjects in this study (Table 2) because our subjects generally exhibited greater exercise capacity than those in previous studies. We also cannot rule out that some subjects, especially those who were younger and had more preserved functional capacity, may have underperformed on the ISWT because subjects performed the classic description of this test in which running is not permitted, ${ }^{19}$ as also recommended for the 6MWT. ${ }^{3}$ Physiological responses on the ISWT should be compared to the CPET to define whether the former can be representative of maximum exercise capacity.

Subjects in this study adopted similar mean velocities during the self-paced test (6MWT) and the externally paced (ESWT) test, which corresponded to, on average, $5.29 \mathrm{~km} / \mathrm{h}$ and $5.04 \mathrm{~km} / \mathrm{h}$, respectively. Therefore, physiological responses during both tests were comparable. We noted that 


\section{Physiologic Responses During Walking Tests}

the velocity maintained by the subjects in this study during the 6MWT and the ESWT matched the preferred walking speed (ie, $5.0 \mathrm{~km} / \mathrm{h}$ or $1.4 \mathrm{~m} / \mathrm{s}$ ) described in healthy adults. ${ }^{23}$

In this study, low ventilatory stress across 3 field walking tests $\left(\dot{\mathrm{V}}_{\mathrm{E}} / \mathrm{MVV}\right.$ 0.18-0.79, Table 2) contrasts with previous studies in subjects with COPD in which the $\dot{\mathrm{V}}_{\mathrm{E}} / \mathrm{MVV}$ ratio was, on average, higher than $90 \% .^{8,10,12}$ However, structural lung damage caused by bronchiectasis has a particular impact on the pulmonary function of patients, with some presenting with normal spirometric data, others showing an obstructive pattern (the more significant proportion of subjects), and a minority presenting with restrictive abnormalities. ${ }^{1}$ Based on the range of the spirometric results of our subjects (Table 1), it is possible that our sample was composed of subjects with normal lung function as well as with air-flow limitations and restrictive patterns. This range of disease severity may have contributed to lower ventilatory stress (ie, the $\dot{\mathrm{V}}_{\mathrm{E}}$ /MVV ratio), which allowed subjects to tolerate higher exercise intensities, given that the majority reached $70-90 \%$ of the maximum predicted heart rate. Despite lower ventilatory demand, the intensity of the limiting symptoms (ie, dyspnea and leg fatigue) corresponded to, on average, a somewhat severe/severe perception of effort, which was similar to those reported in subjects with interstitial lung disease ${ }^{13}$ and $\mathrm{COPD}^{7,9-11}$ during field walking tests.

Abnormal gas exchange during exercise is a common finding in patients with chronic lung diseases, and the walking test is more sensitive than cycling to detect exerciseinduced desaturation in patients with bronchiectasis. ${ }^{2}$ Our study is the first to compare exercise-induced desaturation among field walking tests in this population, and the magnitude of desaturation was comparable across tests. Based on this finding, regardless of the profile (ie, incremental or constant work load) or criteria for discontinuation (ie, time- or symptom-limited), factors such as amount of muscle, relative contribution of metabolism, volume of dead space/tidal volume ratio, body position, lung volumes, and hemodynamic adaptations seem to be equivalent across the field walking tests. ${ }^{6,24}$

\section{Study Limitations}

Physiological demand during field walking tests was not directly compared to CPET, so we cannot express the values achieved at the peak as a percentage of the maximum capacity on CPET. However, based on exercise intensity terminology, our findings suggest that field walking tests elicit vigorous intensity exercise. ${ }^{21}$ Individuals receiving long-term oxygen therapy did not participate in this study, so the results cannot be extrapolated for this subgroup patients. Subjects presented with preserved and abnormal (ie, obstructive and restrictive) patterns on spirometry, but it was not possible to analyze them separately due to the small sample size.

\section{Conclusions}

The profile of cardiometabolic responses differs between the ISWT, 6MWT, and ESWT with an incremental and constant work rate pattern of exercise, although there are no differences in metabolic and ventilatory demands at the peak of the tests. The magnitude of desaturation was similar across tests. On the basis of our results, field walking tests elicit activity of vigorous intensity in subjects with bronchiectasis, which means that these tests can be used interchangeably for evaluation of exercise-induced desaturation.

\section{REFERENCES}

1. Drain M, Elborn JS. Assessment and investigation of adults with bronchiectasis. Eur Respir Mon 2011;52:32-43.

2. Camargo AA, Amaral TS, Rached SZ, Athanazio RA, Lanza FC, Sampaio LM. Incremental shuttle walking test: a reproducible and valid test to evaluate exercise tolerance in adults with non-cystic fibrosis bronchiectasis. Arch Phys Med Rehabil 2014;95(5):892-899.

3. Holland AE, Spruit MA, Troosters T, Puhan MA, Pepin V, Saey D, et al. An official European Respiratory Society/American Thoracic Society technical standard: field walking tests in chronic respiratory disease. Eur Respir J 2014;44(6):1428-1446.

4. Mainguy V, Malenfant S, Neyron AS, Saey D, Maltais F, Bonnet S, Provencher S. Alternatives to the six-minute walk test in pulmonary arterial hypertension. PLoS One 2014;9(8):e103626.

5. Deboeck G, Niset G, Vachiery JL, Moraine JJ, Naeije R. Physiological response to the six-minute walk test in pulmonary arterial hypertension. Eur Respir J 2005;26(4):667-672.

6. Palange P, Forte S, Onorati P, Manfredi F, Serra P, Carlone S. Ventilatory and metabolic adaptations to walking and cycling in patients with COPD. J Appl Physiol 2000;88(5):1715-1720.

7. Turner SE, Eastwood PR, Cecins NM, Hillman DR, Jenkins SC. Physiologic responses to incremental and self-paced exercise in COPD: a comparison of three tests. Chest 2004;126(3):766-773.

8. Troosters T, Vilaro J, Rabinovich R, Casas A, Barberá JA, RodriguezRoisin R, Roca J. Physiological responses to the 6-min walk test in patients with chronic obstructive pulmonary disease. Eur Respir J 2002;20(3):564-569.

9. Casas A, Vilaro J, Rabinovich R, Mayer A, Barberá JA, RodriguezRoisin R, Roca J. Encouraged 6-min walking test indicates maximum sustainable exercise in COPD patients. Chest 2005;128(1):55-61.

10. Luxton N, Alison JA, Wu J, Mackey MG. Relationship between field walking tests and incremental cycle ergometry in COPD. Respirology 2008;13(6):856-862.

11. Hill K, Dolmage TE, Woon L, Coutts D, Goldstein R, Brooks D. Comparing peak and submaximal cardiorespiratory responses during field walking tests with incremental cycle ergometry in COPD. Respirology 2012;17(2):278-284.

12. Zainuldin R, Mackey MG, Alison JA. Prescription of walking exercise intensity from the 6-minute walk test in people with chronic obstructive pulmonary disease. J Cardiopulm Rehabil Prev 2015;35(1):65-69.

13. Holland AE, Dowman L, Fiore JJr, Brazzale D, Hill CJ, McDonald $\mathrm{CF}$. Cardiorespiratory responses to 6-minute walk test in interstitial lung disease: not always a submaximal test. BMC Pulm Med 2014;14:136

14. Vallilo CC, Terra RM, de Albuquerque ALP, Suesada MM, Mariani AW, Salge JM, et al. Lung resection improves the quality of life of patients with symptomatic bronchiectasis. Ann Thorac Surg 2014;98 (3):1034-1041. 


\section{Physiologic Responses During Walking Tests}

15. Pasteur MC, Bilton D, Hill AT, British Thoracic Society Bronchiectasis non-CF Guideline Group. British Thoracic Society guideline for nonCF bronchiectasis. Thorax 2010;65(Suppl 1):i1-i58.

16. Sociedade Brasileira de Pneumologia e Tisiologia. Diretrizes para testes da função pulmonar. J Pneumol 2002;28(Suppl 3):S44-S58.

17. Pereira CAC, Sato T, Rodrigues SC. New reference values for forced spirometry in white adults in Brazil. J Bras Pneumol 2007;33(4):397406.

18. Kovelis D, Segretti NO, Probst VS, Lareau SC, Brunetto AF, Pitta F. Validation of the Modified Pulmonary Functional Status and Dyspnea Questionnaire and the Medical Research Council scale for use in Brazilian patients with chronic obstructive pulmonary disease. J Bras Pneumol 2008;34(12):1008-1018.

19. Singh SJ, Morgan MD, Scott S, Walters D, Hardman AE. Development of a shuttle walking test of disability in patients with chronic airways obstruction. Thorax 1992;47(12):1019-1024.
20. Revill SM, Morgan MD, Singh SJ, Williams J, Hardman AE. The endurance shuttle walk: a new field test for the assessment of endurance capacity in chronic obstructive pulmonary disease. Thorax 1999;54(3):213-222.

21. Norton K, Norton L, Sadgrove D. Position statement on physical activity and exercise intensity terminology. J Sci Med Sport 2010;13(5): 496-502.

22. Hadeli KO, Siegel EM, Sherrill DL, Beck KC, Enright PL. Predictors of oxygen desaturation during submaximal exercise in 8,000 patients. Chest 2001;120(1):88-92.

23. Rose J, Ralson HJ, Gamble JG. Energetics of walking. In: Rose J, Gamble JG, editors. Human Walking. 2nd ed. Baltimore: Williams \& Wilkins; 1994:45-72.

24. Mahler DA, Gifford AH, Waterman LA, Ward J, Machala S, Baird JC. Mechanism of greater oxygen desaturation during walking compared with cycling in patients with COPD. Chest 2011;140(2):351-358. 